\title{
PERBEDAAN KETAHANAN FRAKTUR DAN POLA FRAKTUR PITA SERAT PENGUAT POLIETILEN ANYAMAN LOCKED- STICTHED THREADS DAN BRAIDED SEBAGAI PASAK BUATAN PADA RESTORASI PASCA PERAWATAN ENDODONTI
}

\author{
(FRACTURE RESISTANCE AND MODE OF FRACTURE DIFFERENCES OF LOCKED- \\ STICTHED THREADS AND BRAIDED POLYETHYLENE FIBER REINFORCED \\ RIBBON AS CUSTOMIZED POST IN RESTORATION OF \\ ENDODONTICALLY TREATED TOOTH)
}

\author{
Wandania Farahanny*, Trimurni Abidin*, Harry Agusnar** \\ *Departemen Ilmu Konservasi Gigi \\ Fakultas Kedokteran Gigi, Universitas Sumatera Utara \\ Jl. Alumni No.2 Kampus USU Medan \\ **Departemen Ilmu Kimia Universitas Sumatera Utara \\ Jl. Bioteknologi 1 Kampus USU Medan \\ E-mail: wanda_sidentist@yahoo.com
}

\begin{abstract}
The usage of polyethylene fibre reinforced ribbon with composite resin as customized post and core is gaining popular because it eliminates the need of widening the root canal, therefore minimizing the risk of root fracture. To enhance interfacial adhesions, wettability is gained through the application of wetting. However, clinicians often substitute it with flowable resin. The aim of this study was to evaluate the fracture resistance and mode of fracture of locked-stitched threads and braided fibre reinforced, customized post applied with wetting resin and flowable resin. Forty extracted premolar mandibular teeth with similar size were chosen and randomly divided into four groups. Group A (lockedsticthed+wetting resin), B (locked-sticthed+flowable resin), C (braided+wetting resin) and D (braided+flowable resin). After decoronated and endodontic, the teeth were restored with braided and locked-stitch threads ribbond with wetting and flowable resin. This ribbon treatment were impregnated in dual cured resin cement and composite crown build up. After thermocycling, a compressive load was applied axially at a crosshead speed of $0,5 \mathrm{~mm} / \mathrm{second}$ until fracture using Universal Testing Machine. Fracture loads and fracture modes were recorded. ANOVA statistical test showed that there was no significant difference $(\mathrm{p}=0.367)$ in fracture resistance of customized post consisted of polyethylene fibres with different configuration and wettability. It was concluded that locked-stitched and braided polyethylene fibre reinforced, customized post have similar fracture resistance, whether applied with wetting or flowable resin. Nevertheless, it was noted that mode of fracture with wetting is more repairable than flowable resin.
\end{abstract}

Key words: fracture resistance, polyethylene fiber reinforced ribbon, post

\begin{abstract}
Abstrak
Penggunaan bahan adhesif pita serat penguat polietilen dengan resin komposit sebagai pasak buatan semakin banyak diminati. Pemasangan pasak ini tidak membutuhkan pelebaran saluran akar yang lebih banyak sehingga dapat mengurangi risiko terjadinya fraktur akar. Wetting resin dipakai sebagai wettability untuk meningkatkan perlekatan interfasial. Terkadang para klinisi sering menggunakan flowable resin sebagai penggantinya. Penelitian ini bertujuan untuk mengetahui ketahanan fraktur penggunaan pita serat penguat poli etilen anyaman braided dan locked-sticthed threads sebagai pasak buatan pada restorasi pasca perawatan endodonti dengan aplikasi wetting resin dan flowable resin. Empat puluh gigi premolar mandibular yang telah diekstraksi dan memiliki ukuran sama dibagi menjadi empat kelompok. Kelompok A (locked-sticthed+wetting resin), B (locked-sticthed+flowable resin), C (braided+wetting resin) dan D (braided+flowable resin). Setelah pemotongan mahkota dan perawatan endodonti dilakukan pemasangan pasak buatan. Pita dibenamkan ke dalam semen resin dual cured dan dilanjutkan dengan pembentukan mahkota dari resin komposit. Setelah thermocycling, dilakukan uji tekan searah aksial gigi dengan kecepatan 0,5mm/detik sampai terjadi
\end{abstract}


fraktur menggunakan Universal Testing Machine. Nilai beban fraktur dan pola fraktur yang terjadidicatat. Hasil uji statistik Anova menunjukkan tidak terdapat perbedaan signifikan pada ketahanan fraktur pasak buatan pita serat penguat dengan pola anyaman dan wettability yang berbeda $(\mathrm{p}=0,367)$. Dengan adanya keterbatasan penelitian ini, pola fraktur pasak fiber anyaman locked-sticthed threads dan braided dengan wetting resinmenunjukkan 80-90\% mudah direstorasi kembali. Sebagai kesimpulan, penggunaan pita serat penguat polietilen sebagai pasak buatan dengan anyaman berbeda memiliki ketahanan fraktur yang sama. Akan tetapi, pola fraktur pada pasak yang menggunakan wetting resin lebih mudah direstorasi kembali dibandingkan dengan flowable resin.

Kata kunci: ketahanan fraktur, serat penguat polietilen, pasak

\section{PENDAHULUAN}

Pemakaian sistem pasak dan inti sebagai retensi intra-radikular merupakan salah satu usaha yang dilakukan dokter gigi untuk memberikan kekuatan tambahan pada rekontruksi mahkota setelah perawatan endodonti. Tujuan penggunaan pasak didalam saluran akar adalah menjadi fondasi restorasi diatasnya, sedangkan inti dapat meningkatkan retensi pada mahkota gigi. Kehilangan struktur gigi bagian mahkota karena karies yang luas, pembukaan akses dan pelebaran saluran akar pada perawatan endodonti menyebabkan dinding saluran akar menjadi tipis. Semakin sedikit struktur gigi yang tersisa semakin kecil kekuatan gigi untuk menahan beban pengunyahan sehingga risiko terjadinya fraktur pada gigi pasca endodonti lebih tinggi. Oleh sebab itu gigi pasca endodonti yang mengalami kehilangan banyak struktur gigi menjadi indikasi pemasangan sistem pasak. ${ }^{1}$

Idealnya sistem pasak harus dapat menggantikan struktur gigi yang hilang, memiliki modulus elastisitas yang menyerupai dentin, mudah dikeluarkan dari saluran akar jika diperlukan perawatan ulang, biokompatibel, memiliki dukungan retensi, dan mampu mendistribusi tekanan oklusal pada saat aktivitas fungsional. Apabila sistem pasak mampu menyalurkan tekanan keseluruh struktur akar dengan merata, kemungkinan terjadinya fraktur akar dapat diminimalkan. Akan tetapi, banyak laporan kasus yang menunjukkan pemasangan pasak pada restorasi akhir mengakibatkan fraktur pada akar sehingga gigi tidak dapat diperbaiki dan harus dilakukan ekstraksi. Hal ini merupakan salah satu kegagalan yang sering terjadi pada perawatan endodonti. ${ }^{2}$

Klasifikasi pasak dapat dibedakan berdasarkan jenis bahan dan cara pembuatannya. Berdasarkan cara pembuatannya pasak terdiri atas pasak jadi (prefabricated) dan dibuat sendiri oleh operator (customized). Sedangkan berdasarkan jenis bahan pasak terbagi menjadi pasak metal dan non metal. ${ }^{3}$ Selama ini pasak metal mempunyai beberapa permasalahan yang sering dijumpai di klinis. Salah satunya adalah terjadinya perubahan warna karena bahan metal mengalami korosi, pasak longgar karena terjadi pergeseran antara pasak dengan dinding struktur gigi, sulit untuk dilakukan pembongkaran pada kasus perawatan ulang dan terjadinya fraktur pada akar gigi. ${ }^{4}$

Penggunaan fiber sebagai pasak non metal setelah pasca perawatan endodonti menjadi mulai popular karena memiliki banyak keuntungan. ${ }^{4}$ Beberapa hasil penelitian menunjukkan pasak fiber memiliki perlekatan yang sangat baik dengan bahan berbasis resin dengan memanfaatkan sistem adhesif. Modulus elastisitas fiber menyerupai dentin sehingga mampu mendistribusikan tekanan secara merata. Oleh sebab itu, pasak fiber dapat mengurangi risiko terjadinya fraktur akar dibandingkan pasak metal. ${ }^{5-6}$

Pasak fiber buatan pabrik (prefabricated) banyak digunakan para klinisi karena lebih estetis dibandingkan pasak metal. Namun prosedur pemasangan pasak buatan pabrik tetap membutuhkan pembuangan dentin radikular untuk persiapan ruang pasak dan adaptasi dalam saluran akar. Hal ini mengakibatkan struktur dentin banyak terbuang sehingga dinding saluran akar menjadi lebih tipis dan menjadi predisposisi terjadinya fraktur akar. ${ }^{5-7} \mathrm{Ke}-$ lemahan pasak fiber buatan pabrik juga tidak dapat menyesuaikan dengan bentuk saluran akar karena sudah tersedia dalam bentuk sediaan jadi., ${ }^{2,46}$

Saat ini bahan fiber dikembangkan menjadi susunan pita serat penguat dari bahan glass atau polietilen. ${ }^{6}$ Pita ini dapat digunakan sebagai pasak buatan dengan memanfaatkan perlekatan adhesif. ${ }^{7}$ Sistem ini dikategorikan sebagai pasak buatan karena dibuat oleh operator dengan cara memasukkan anyaman pita serat penguat ke dalam saluran pasak yang sudah diaplikasikan semen luting resin terlebih dahulu. Pembuatan sistem pasak dapat sekaligus membangun inti dan mahkota klinis dari resin komposit secara direk. ${ }^{3,8}$

Piovesan dkk. ${ }^{9}$ melakukan penelitian yang dilakukan pada 69 pasien yang direstorasi dengan pasak buatan dari pita serat penguat polietilen anyaman locked sticthed threads selama 97 bulan, secara keseluruhan hasilnya menunjukkan $90,2 \%$ gigi tersebut masih bertahan di rongga mulut. Turker dkk. ${ }^{10}$ 
melakukan penelitian pasak fiber buatan dengan pita serat penguat locked sticthed threads pada 42 gigi (31 gigi anterior dan 11 gigi posterior) selama 10-73 bulan, hasilnya menunjukkan hanya 1 gigi yang mengalami kegagalan adhesif antara dentin dan semen luting yang mengakibatkan lepasnya pasak. Hal ini menunjukkan pasak buatan dari pita serat penguat polietilen mempunyai keberhasilan klinis yang cukup tinggi. ${ }^{8-10}$

Konfigurasi pita serat penguat memiliki variasi susunan pola anyaman seperti mesh, weave, unidirectional, braided dan locked stitched treads. ${ }^{6}$ Konfigurasi pola anyaman pita fiber yang berbeda dapat mempengaruhi perlekatan interfasial antara fiber dengan resin matriks yang secara tidak langsung dapat menentukan ketahanan fraktur. ${ }^{2}$ Beberapa merek pita serat penguat polietilen yang ada saat ini dipasaran seperti Ribbond ${ }^{\circledR}$ (USA) dan Construct (Kerr) yang memiliki perbedaan dalam hal pola anyaman. $^{5}$

Perlekatan interfasial yang optimal antara fiber dengan semen resin memerlukan wettability yang sempurna agar menghasilkan mekanikal properti bahan yang kuat. Intruksi pabrik menganjurkan pemakaian wetting resin (resin tanpa filler) sebagai wettability pita fiber. Akan tetapi, pemakaian di klinik sering digantikan dengan flowable resin yang biasa digunakan untuk pit and fissure sealant. ${ }^{5,6}$

Berdasarkan penelusuran kepustakaan yang ada hingga saat ini belum ada penelitian mengenai aplikasi wetting resin dan flowable resin pada sistem pasak buatan menggunakan pita penguat polietilen dengan pola anyaman berbeda terhadap ketahanan fraktur. Ketahanan fraktur adalah kemampuan gigi dapat menahan beban ketika berfungsi tanpa mengalami fraktur gigi. ${ }^{1,8}$

Tujuan penelitian ini adalah untuk mengetahui perbedaan ketahanan fraktur dan pola fraktur penggunaan pita serat penguat polietilen anyaman braided dan locked-sticthed threads dengan wetting resin dan flowable resin sebagai pasak buatan pada restorasi pasca perawatan endodonti.

\section{BAHAN DAN METODE}

Jenis penelitian ini adalah penelitian eksperimental laboratorium dengan rancangan posttest only group design. Penelitian dilakukan pada empat puluh gigi premolar mandibular yang telah diekstraksi untuk keperluan ortodonti. Gigi yang digunakan memiliki kriteria saluran akar tunggal, akar gigi masih utuh, ukuran panjang akar gigi $\pm 16-17 \mathrm{~mm}$, tidak ada karies akar dan tidak retak. Preparasi ferul dibuat untuk menghindari rotasi dengan cara membuang mahkota gigi sampai batas $2 \mathrm{~mm}$ diatas cemento enamel juntion dengan menggunakan disc bur. Kemudian dilakukan perawatan endodonti dengan teknik step back menggunakan K-File (FKG dentaire, Swiss) sesuai dengan panjang kerja dengan irigasi larutan $\mathrm{NaOCl} 5 \%$. Gigi yang telah dipreparasi dilakukan obturasi dengan menggunakan gutta percha dengan teknik kondensasi lateral dan vertikal. Persiapan ruang untuk pasak dilakukan dengan membuang gutta percha yang sudah padat dengan menggunakan peaso reamer (FKG dentaire, Swiss) sampai $2 / 3$ panjang akar dan meninggalkan gutta percha sebanyak 4-5 mm sebagai penutupan apikal.

Aplikasi bahan adhesif sistem two step bonding (ParaBond, Coltene Whaledent) dilakukan pada seluruh permukaan dinding saluran akar sesuai petunjuk pabrik. Sampel gigi dibagi menjadi 4 kelompok yang mana setiap kelompok terdiri atas 10 gigi. Pada penelitian ini digunakan dua jenis pita serat penguat polietilen yang memiliki pola anyaman berbeda yaitu anyaman locked stiched threads (Ribbond, USA) dan braided (Construct, KERR). Kelompok A, pita polyethylene fiber reinforced anyaman locked stiched threads dengan aplikasi wetting resin (Ribbond,USA). Kelompok B, pita polyethylene fiber reinforced anyaman locked stiched threads dengan aplikasi flowable resin (Filtek Z350,3 M). Kelompok C, pita polyethylene fiber reinforced anyaman braided dengan aplikasi wetting resin. Kelompok D, pita polyethylene fiber reinforced anyaman braided dengan aplikasi flowable resin. Pemotongan pita polyethylene fiber reinforced dilakukan dengan gunting khusus fiber. Kemudian potongan pita fiber ini dimasukkan ke dalam saluran akar yang sudah diisi dengan semen luting resin dual cured dan sekaligus pembentukan bagian inti. Mahkota klinis dibentuk menggunakan resin komposit (Filtek P60, 3M) secara inkremental dan dilakukan penyinaran dengan light cured LED (Mr. Light, China). Setelah konturing dan pemolesan, seluruh sampel dilakukan thermocycling pada temperatur $5^{\circ} \mathrm{C}$ dan $55^{\circ} \mathrm{C}$ selama 15 detik dengan waktu transfer 5 detik. Untuk uji ketahanan fraktur, seluruh sampel gigi ditanam dalam balok akrilik dan proses uji tekan diaplikasikan searah aksial gigi dengan kecepatan $0,5 \mathrm{~mm} /$ detik sampai terjadi fraktur menggunakan Torsee's (Universal Testing Machine, Tokyo, Japan). Dilakukan pencatatan load dalam satuan Newton. Pengamatan pola fraktur dilakukan oleh dua orang pengamat untuk menghindari bias. Lokasi pola fraktur dikelompokkan menjadi fraktur inti, fraktur inti+mahkota, fraktur akar dan retak vertikal. Data pola fraktur hanya dilihat secara deskriptif, sedangkan perbedaan load ketahanan fraktur 
antara kelompok dianalisis dengan uji ANOVA.

\section{HASIL}

Hasil penelitian menunjukkan nilai rerata ketahanan fraktur tertinggi adalah pada kelompok pasak pita braided dengan aplikasi wetting resin 1506,06 Newton. Sedangkan nilai rerata paling rendah adalah 1178,45 Newton pada kelompok pasak pita locked sticthed threads dengan aplikasi flowable resin (Tabel 1). Hasil uji statistik Anova menunjukkan tidak ada perbedaan yang signifikan ketahanan fraktur pada seluruh kelompok perlakuan ( $p>0,05)$.

Tabel 1. Hasil uji statistik ketahanan fraktur sistem pasak dengan pita fiber reinforced dengan menggunakan pola anyaman dan wettability yang berbeda

\begin{tabular}{lcc}
\hline \multicolumn{1}{c}{ Kelompok } & \multicolumn{2}{c}{ Ketahanan fraktur dalam Newton } \\
\cline { 2 - 3 } & & $\mathrm{X} \pm \mathrm{SD}$ \\
\hline $\begin{array}{l}\text { Pasak dengan anyaman locked } \\
\text { stitched threads }+ \text { Weting Resin } \\
\text { (A) }\end{array}$ & $1374.05 \pm 317.94$ \\
$\begin{array}{l}\text { Pasak dengan anyaman locked } \\
\text { stitched threads }+ \text { Flowable }\end{array}$ & $1178.45 \pm 286.74$ & 0,367 \\
$\begin{array}{l}\text { Resin }(\mathrm{B}) \\
\text { Pasak dengan anyaman braided } \\
+ \text { Weting Resin }(\mathrm{C})\end{array}$ & $1506.06 \pm 529.66$ \\
$\begin{array}{l}\text { Pasak dengan anyaman braided } \\
+ \text { Flowable Resin(D) }\end{array}$ & $1308.20 \pm 469.46$ \\
\hline
\end{tabular}

Tabel 2 menunjukkan hasil pengamatan pola fraktur pada pasak fiber dengan aplikasi wetting resin 80 dan $90 \%$ dapat direstorasi kembali (repairable). Sedangkan pasak fiber dengan aplikasi flowable re$\sin$ menunjukkan pola fraktur 40 dan $50 \%$ tidak dapat direstorasi kembali (irrepairable). Bentuk pola fraktur yang terjadi terlihat pada Gambar 1a, 1b, 2a dan $2 b$.

Tabel 2. Data hasil pengamatan bentuk pola fraktur setelah uji ketahanan fraktur

\begin{tabular}{|c|c|c|c|c|c|c|}
\hline \multirow[b]{2}{*}{$\begin{array}{c}\text { Kelompok } \\
\text { Pasak Customized }\end{array}$} & \multicolumn{3}{|c|}{ Repairable (R) \% } & \multicolumn{3}{|c|}{ Irrepairable (IR) \% } \\
\hline & $\begin{array}{c}\text { Fraktur } \\
\text { Inti }\end{array}$ & $\begin{array}{l}\text { Fraktur } \\
\text { Pasak \& } \\
\text { Inti }\end{array}$ & Total & $\begin{array}{c}\text { Fraktur } \\
\text { Akar }\end{array}$ & $\begin{array}{l}\text { Retak } \\
\text { Vertikal } \\
\text { sampai } \\
\text { akar }\end{array}$ & Total \\
\hline $\begin{array}{l}\text { Anyaman locked } \\
\text { stitched threads } \\
+ \text { WetingResin(A) }\end{array}$ & 80 & - & 80 & 10 & 10 & 20 \\
\hline $\begin{array}{l}\text { Anyaman locked } \\
\text { stitched threads } \\
+ \text { Flowable Resin } \\
\text { (B) }\end{array}$ & 50 & - & 50 & 30 & 20 & 50 \\
\hline $\begin{array}{l}\text { Anyaman braided } \\
+ \text { Weting Resin }(\mathrm{C})\end{array}$ & 70 & 20 & 90 & - & 10 & 10 \\
\hline $\begin{array}{l}\text { Anyaman braided } \\
+ \text { Flowable Resin } \\
\text { (D) }\end{array}$ & 40 & 20 & 60 & 20 & 20 & 40 \\
\hline
\end{tabular}
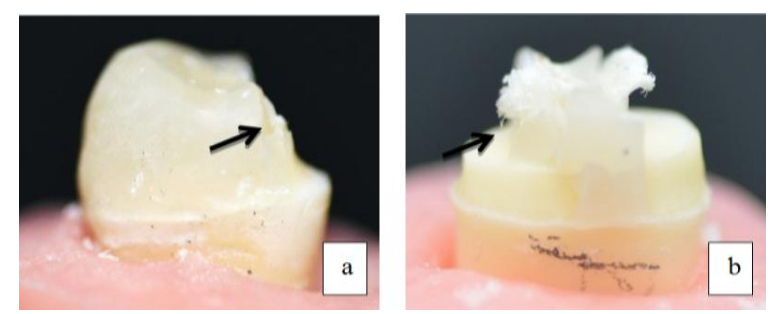

Gambar 1. Pola fraktur sampel repairable yaitu: fraktur pada inti (a), fraktur pada pasak dan inti (b)
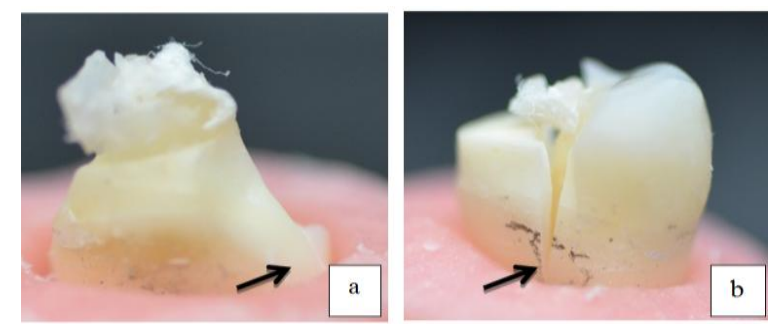

Gambar 2. Pola fraktur sampel irrepairabler yaitu: fraktur akar (a), retak vertikal sampai akar (b)

\section{PEMBAHASAN}

Penelitian ini menggunakan sistem pasak buatan dari pita serat penguat polietilen dengan dua pola anyaman berbeda. Aplikasi pita anyaman braided lebih sulit dimasukkan kedalam saluran akar dibandingkan pita anyaman locked stitched threads.

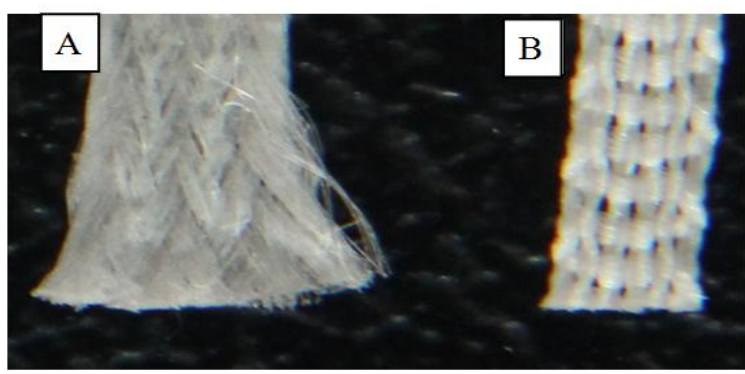

Gambar 3. Pita polyethylene fiber reinforced dengan pola anyaman braided (A), pola anyaman locked stitched threads $(\mathrm{B})$

Pada saat pemotongan, bagian tepi jalinan fiber pola anyaman braided mudah terurai (Gambar 3a), sedangkan pita anyaman locked stitched threads tepi jalinan fiber tetap rata (Gambar 3b). Oleh sebab itu aplikasi pita anyaman locked stitched threads lebih mudah dilakukan (easy handling).

Pada penelitian ini, nilai load ketahanan fraktur sistem pasak fiber anyaman pita braided dengan locked stitched threads, baik dengan aplikasi wetting resin dan flowable resin terlihat tidak ada perbedaan yang signifikan ( $p>0,05)$. Hal ini mungkin disebabkan kedua bahan pita serat penguat polietilen 
bersifat adhesif dan memiliki kemampuan yang sama dalam hal menyerap dan mendistribusikan tekanan pada seluruh permukaan dinding akar gigi dari load yang diberikan pada pasak. ${ }^{10,11}$ Mekanisme distribusi tekanan pada pasak fiber yang terjadi sesuai dengan teori konsep monoblock. ${ }^{12}$

Karakteristik seluruh bahan yang digunakan dalam pembuatan pasak buatan memiliki sifat dan modulus elastisitas yang menyerupai dentin yang di mana modulus elastisitas kombinasi serat penguat polietilen dengan sistem adhesif 23,6 GPa mendekati modulus elastisitas dentin $20 \mathrm{GPa} .{ }^{6,7} \mathrm{Hal}$ ini yang menyebabkan distribusi tekanan pasak ke struktur gigi menjadi homogen. Apabila tekanan dapat didistribusikan dengan optimal maka kemungkinan terjadi fraktur menjadi lebih minimal. ${ }^{8}$

Nilai rerata ketahanan fraktur tertinggi terlihat pada kelompok pasak fiber pita anyaman braided dengan aplikasi wetting resin yaitu 1506.06 Newton. Serat pada anyaman braided yang masuk ke dalam saluran akar tersebar memenuhi ruang, menyatu dengan semen resindan dentin bonding sehingga efek memperkuat struktur akar gigi menjadi lebih besar. $^{11}$

Sesuai dengan penelitian Torabi dan Fattahi yang menunjukkan ketahanan fraktur pasak fiber buatan pabrik dan pasak buatan operator tidak ada perbedaan yang signifikan, akan tetapi pola fraktur yang terjadi pada kelompok pasak fiber menunjukkan fraktur yang repairable. ${ }^{1}$ Pita serat penguat polietilen yang diletakkan pada bahan resin komposit bagian koronal akan berfungsi sebagai crack stopper sehingga menghambat kecepatan rambatan retakan. Pita serat penguat polietilen memberikan efek reinforced pada restorasi interimresin komposit. ${ }^{7,11}$

Hasil penelitian ini menunjukkan pasak fiber buatan dengan aplikasi wetting resin menunjukkan pola fraktur 80 dan $90 \%$ repairable sedangkan pola fraktur yang terjadi pada kelompok pasak dengan aplikasi flowable resin $40 \%$ dan $50 \%$ irrepairable. Hal ini dapat terjadi karena adanya perbedaan kemampuan wettability dari kedua bahan wetting resin dan flowable resin. Larutan wetting resin lebih cair dibandingkan flowable resin yang lebih kental. Kemampuan mengalir dan membasahi permukaan pita fiber dan jalinan polyethylene fiber reinforced lebih optimal pada wetting resin dibandingkan flowable resin. Sudut kontak pembasahan pada wetting resin lebih kecil sehingga lebih memungkinkan membasahi seluruh permukaan dengan rata sehingga dapat meningkatkan adhesi interfasial dan mengurangi terbentuknya gap. ${ }^{6}$ Adanya gap pada adhesi interfasial dapat menjadi penyebab microcrack dan intial crack yang dapat berkembang men- jadi crack propagation dan pada akhirnya terjadi fraktur. ${ }^{8}$

Pita serat penguat polietilen dengan pola anyaman braided pada daerah inti menyebar seperti akar serabut dan menumpuk pada daerah mahkota sehingga tekanan yang diterima dapat ditransfer dari satu serat ke serat lainnya. ${ }^{7}$ Oleh sebab itu, efek penguat dan penahan retakan yang terjadi pada pita braided menjadi lebih besar dibandingkan pita locked stiched threads.

Berdasarkan hasil penelitian ini dapat disimpulkan, pita serat penguat polietilen pola anyaman locked-sticthed dan braided dengan aplikasi wetting resin dan flowable resin sebagai pasak buatan memiliki ketahanan fraktur yang sama. Akan tetapi pola fraktur yang terjadi pada aplikasi wetting resin lebih banyak terjadi pada bagian koronal sehinga mudah direstorasi kembali (repairable) dibandingkan dengan aplikasi flowable resin.

\section{Daftar Pustaka}

1. Torabi K, Fattahi F. Fracture resistance of endodontically treated teeth restored by different FRC posts: an in vitro study. Indian J Dent Res 2009; 20(3): 282-7.

2. Le Bell-Rönnlöf AM. Fibre-reinforced composites as root canal posts. Thesis. Finland, Turku: University of Turku, 2007: 16-36.

3. Cheung W. A Review of the management of endodontically treated teeth: Post, core and the final restoration. JADA 2005; 136: 611-19.

4. Glazer B. Endodontic post evolution from metal to quartz. Oral Health 2002: 43-5.

5. Terry DA. Design principles for the direct fiberreinforced composite resin post and core system. Contemporary Esthetis and Restorative Practice 2003; 22-31.

6. Ferrari, M. Fiber posts and edodontically treated teeth: a compendium of scientific and clinical perspectives. Wendywood: Modern Dentistry Media, 2008: 15-37.

7. Belli S, Eskitasciogiu G. Biomechanical properties and clinical use of a polyethylene fibre post-core material. Int Dentistry South Africa; 8(3): 20-6.

8. Kishen A. Mechanisms and rick factors for fracture predilection in encocontically treated teeth; Endodontic Topic. Blackweel Munksgaard 2006; 13: 57-83.

9. Piovesan EM, Demarco FF, Cenci MS, Cenci TP. Survival rates of endodontically treated teeth restored with fiber-reinforced custom posts and cores: a 97-month study. Int J Prosthodont 2007: 633-9.

10. Turker SB, Alkumru HN, Evren B. Prospective clinical trial of polyethylene fiber ribbond-reinforced, resin composite post-core buildup restora- 
tions. Int J Prosthodont 2007: 55-6.

11. Deliperi S, Bardwell DN, Coiana C. Reconstruction of devital teeth using direct fiber-reinforced composite resins: a case report. J Adhes Dent 2005; 7(2):
$1-7$.

12. Tay FR, Pashley DH. Monoblock in root canals-a hypothetical or tangible goal. J Endod 2007; 33(4): 391-8. 